\title{
Simple and accurate quantification of BTEX in ambient air by SPME and GC-
}

\section{MS}

\section{Nassiba Baimatova ${ }^{1}$, Bulat Kenessov ${ }^{1 *}$, Jacek A. Koziel ${ }^{2}$, Lars Carlsen ${ }^{3}$, Marat Bektassov ${ }^{1}$, Olga P. Demyanenko ${ }^{1}$}

${ }^{1}$ Al-Farabi Kazakh National University, Faculty of Chemistry and Chemical Engineering, Center of Physical Chemical Methods of Research and Analysis, Almaty, Kazakhstan. baimatova@cfhma.kz; bkenesov@cfhma.kz

${ }^{2}$ Iowa State University, Department of Agricultural and Biosystems Engineering, Ames, IA, 50011, USA,koziel@iastate.edu

${ }^{3}$ Awareness Center, Trekroner, DK-4000 Roskilde, Denmark, LC@AwarenessCenter.dk

* - Corresponding author, 050012 Almaty, 96a Tole bi Street, lab. 101, Kazakhstan, tel: +7 727 2921374; fax: +7 727 2923731; e-mail: bkenesov@cfhma.kz.

\begin{abstract}
Benzene, toluene, ethylbenzene and xylenes (BTEX) comprise one of the most ubiquitous and hazardous groups of ambient air pollutants of concern. Application of standard analytical methods 
for quantification of BTEX is limited by the complexity of sampling and sample preparation equipment, and budget requirements. Methods based on SPME represent simpler alternative, but still require complex calibration procedures. The objective of this research was to develop a simpler, low-budget, and accurate method for quantification of BTEX in ambient air based on SPME and GC-MS. Standard 20-mL headspace vials were used for field air sampling and calibration. To avoid challenges with obtaining and working with required 'zero' air, slope factors of external standard calibration were determined using standard addition and an inherently polluted lab air. For polydimethylsiloxane (PDMS) fiber, differences between slope factors of calibration plots obtained using lab and outdoor air were below 14\%. PDMS fiber provided higher precision during calibration while the use of Carboxen/PDMS fiber resulted in lower detection limits for benzene and toluene. To provide sufficient accuracy, the use of $20 \mathrm{~mL}$ vials requires triplicate sampling and analysis. The method was successfully applied for analysis of 108 ambient air samples from Almaty, Kazakhstan. Average concentrations of benzene, toluene, ethylbenzene and $o$-xylene were 53, 57, 11 and $14 \mu \mathrm{g}$ $\mathrm{m}^{-3}$, respectively. The developed method can be modified for further quantification of a wider range of volatile organic compounds in air. In addition, the new method is amenable to automation.

Keywords: solid-phase microextraction; GC-MS; standard addition; BTEX; ambient air pollution; air analysis.

\section{Introduction}

According to the World Health Organization (WHO), in 2012, outdoor air pollution was responsible for the death of 3.7 million people under the age of $60,90 \%$ of whom lived in developing countries [1]. Within hazardous volatile organic compounds (VOCs), special attention is placed on benzene, toluene, ethylbenzene and $o-, p$-and $m$-xylenes (BTEX) emitted to the 
atmosphere from both anthropogenic and biogenic sources [2]. BTEX pose a serious threat to human health [3], with benzene as a known carcinogen [4,5].

Standard approaches currently used for quantification of BTEX [6-8] are primarily based on trapping analytes onto sorbent tubes followed by thermal desorption, cryogenic focusing and analysis by gas chromatography (GC). Despite of good reliability, these techniques are quite complex, labor and time intensive, and require additional (often expensive) sampling and sample preparation equipment. This significantly limits the capabilities for air monitoring in many developing countries having serious air quality problems.

Compared to standard methods, solid-phase microextraction (SPME) [9-11] constitutes an attractive alternative technique for screening and quantification of VOCs in air. It is based on a passive extraction of VOCs by a thin polymer coating followed by desorption of analytes in a GC injection port. The use of SPME does not require a canister interface or a thermal desorption unit, which are needed for standard methods. Desorption of VOCs from SPME is rapid; it does not require cryogenic focusing and can be automated.

Available SPME-based methods for quantification of VOCs in ambient and indoor air (summarized in Table 1) are based on the following few approaches:

- $\quad$ exposing a fiber to a whole analyzed air;

- $\quad$ exposing a fiber to air sample captured inside a sampling bag or a calibrated bulb;

- $\quad$ time-weighted extraction of air by the fiber retracted inside a protecting needle.

Table 1. Comparison of relevant SPME-based methods for determination of VOCs in ambient air

\begin{tabular}{|l|c|c|c|c|}
\hline \multicolumn{1}{|c|}{ Authors } & $\begin{array}{c}\text { Calibration standards } \\
\text { preparation }\end{array}$ & $\begin{array}{c}\text { Sampling and } \\
\text { sample preparation } \\
\text { procedure }\end{array}$ & Advantages & Disadvantages \\
\hline $\begin{array}{l}\text { Chai and } \\
\text { Pawliszyn, } \\
1995[12]\end{array}$ & $\begin{array}{c}\text { Spiking standards } \\
\text { dissolved in } \\
\text { dichloromethane to a } \\
\text { 1-L calibrated bulb }\end{array}$ & $\begin{array}{c}\text { Sampling to 6-L } \\
\text { canisters, purging the } \\
\text { sampled air via the } \\
\text { bulb }\end{array}$ & $\begin{array}{c}\text { 1) Simple } \\
\text { calibration } \\
\text { 2) High accuracy } \\
\text { of a calibrated }\end{array}$ & $\begin{array}{c}\text { 1) Thorough bulb } \\
\text { cleaning is required } \\
\text { 2) High-purity } \\
\text { helium is required }\end{array}$ \\
\hline
\end{tabular}




\begin{tabular}{|c|c|c|c|c|}
\hline $\begin{array}{l}\text { Chai and } \\
\text { Tang, } 1998 \\
{[13]}\end{array}$ & $\begin{array}{c}\text { filled with a pure } \\
\text { helium }\end{array}$ & & bulb volume & $\begin{array}{l}\text { 3) Only manual } \\
\text { calibration is } \\
\text { possible } \\
\text { 4) Limited number } \\
\text { of samples may be } \\
\text { analyzed due to high } \\
\text { cost and mass of } \\
\text { canisters }\end{array}$ \\
\hline $\begin{array}{l}\text { Hippelein, } \\
2006 \text { [14] }\end{array}$ & $\begin{array}{l}\text { Spiking } 60 \mu \mathrm{L} \text { of } \\
\text { standards dissolved in } \\
\text { methanol to gas } \\
\text { sampling bags } \\
\text { (volume and matrix } \\
\text { composition of } \\
\text { calibration sample is } \\
\text { unknown) }\end{array}$ & $\begin{array}{l}10 \text {-min fiber } \\
\text { exposure to the } \\
\text { analyzed air }\end{array}$ & $\begin{array}{l}\text { 1) Simple } \\
\text { calibration } \\
\text { 2) Ideal for on-site } \\
\text { measurements }\end{array}$ & $\begin{array}{l}\text { 1) Sampling volumes } \\
\text { during calibration } \\
\text { and extraction are } \\
\text { different and may } \\
\text { affect response of } \\
\text { analytes } \\
\text { 2) Fiber may } \\
\text { extract/desorb } \\
\text { analytes during } \\
\text { transportation } \\
\text { 3) High cost of fibers } \\
\text { due to single use per } \\
\text { sample collection }\end{array}$ \\
\hline $\begin{array}{l}\text { Martos and } \\
\text { Pawliszyn, } \\
1997 \text { [15] } \\
\text { Koziel and } \\
\text { Pawliszyn, } \\
2001 \text { [16] } \\
\text { Tuduri et } \\
\text { al., 2001 } \\
\text { [17] } \\
\text { Tumbiolo et } \\
\text { al., 2004 } \\
\text { [18] } \\
\text { Tumbiolo et } \\
\text { al., 2005 } \\
\text { [19] }\end{array}$ & $\begin{array}{l}\text { Supplying mixture of } \\
\text { pure analytes at a } \\
\text { known rate to a } \\
\text { known flow rate of air } \\
\text { - standard gas } \\
\text { generation system. }\end{array}$ & $\begin{array}{c}\text { Fiber exposure at the } \\
\text { analyzed air }\end{array}$ & $\begin{array}{l}\text { 1) Closest to real } \\
\text { conditions } \\
\text { calibration - } \\
\text { highest accuracy } \\
\text { may be achieved } \\
\text { 2) Low detection } \\
\text { limits }\end{array}$ & $\begin{array}{l}\text { 1) 'Zero' air is } \\
\text { required } \\
\text { 2) Complex standard } \\
\text { gas generation } \\
\text { system is required } \\
\text { 3) Fiber may } \\
\text { extract/desorb } \\
\text { analytes during } \\
\text { transportation } \\
\text { 4) High cost of fibers } \\
\text { due to single use per } \\
\text { sample collection }\end{array}$ \\
\hline This study & $\begin{array}{l}\text { Spiking standards } \\
\text { dissolved in methanol } \\
\text { to } 20-\mathrm{mL} \text { vials filled } \\
\text { with lab (non-'zero', } \\
\text { contaminated) air }\end{array}$ & $\begin{array}{l}\text { Sampling to three } \\
\text { replicate } 20-\mathrm{mL} \text { vials } \\
\text { stored in } 1 \mathrm{~L} \text { jars } \\
\text { filled with a sampled } \\
\text { air }\end{array}$ & $\begin{array}{l}\text { 1) Automatic } \\
\text { calibration and } \\
\text { analysis of } \\
\text { samples is } \\
\text { possible } \\
\text { 2) Simple, robust } \\
\text { and low-cost } \\
\text { approach } \\
\end{array}$ & $\begin{array}{l}\text { 1) Potential in-vial } \\
\text { transformation of } \\
\text { analytes } \\
\text { 2) Special care must } \\
\text { be taken to avoid } \\
\text { sample leaks via } \\
\text { septa }\end{array}$ \\
\hline
\end{tabular}


In spite of the high efficiency of all three approaches, they require labor intensive calibration and still have a limited applicability to real ambient air monitoring, which involve analyses of a large number of samples. Controlling the boundary layer around SPME fiber, which impacts extraction rate, can limit the direct use of SPME in the field. Time-weighted average SPME with retracted fiber addresses the control of the boundary layer, but can still be associated with insufficient accuracy due to temperature fluctuations during sampling and adsorption of analytes onto metallic parts of the fiber attachment [20]. Consequently, only few applications of SPME dealing with real air monitoring and representing analysis of a low number of samples have been published. Thus, there is a need for a simple and accurate analytical method utilizing SPME for quantification of volatile air pollutants, so the SPME could have a greater adoption in air quality studies. Specifically, greater adoption of SPME will help minimizing the requirement for (or elimination of) specialized air sampling, sample preparation and sample introduction equipment.

The objective of this research was to develop a simple and accurate method for quantification of BTEX in ambient air using SPME and GC-MS. For the method simplification, standard 20-mL headspace vials were used for sampling and calibration (Table 1). To avoid challenges with obtaining and working with required 'zero' air, slope factors of external standard calibration were determined using standard addition approach and a laboratory air. The developed method was successfully applied for the analysis of an ambient air in Almaty, the most populated city in Kazakhstan with a highly contaminated air [21]. 


\section{Experimental}

\subsection{Standards, solvents and SPME fibers}

Benzene (99.8\%) and toluene (99.8\%) were obtained from EKOS-1 LLP (Moscow, Russia). Ethylbenzene (99.0\%), and $o$-xylene (99.0\%) were purchased from Sigma-Aldrich, St. Louis, MO, USA. Methanol (HPLC grade) was obtained from AppliChem (Darmstadt, Germany). Helium (>99.995\%) was purchased from Orenburg-Tehgas (Orenburg, Russia). SPME fibers $-100 \mu \mathrm{m}$ polydimethylsiloxane (PDMS), $85 \mu \mathrm{m}$ Carboxen (CAR)/PDMS and $65 \mu \mathrm{m}$ PDMS/divinylbenzene (DVB), were obtained from Supelco (Bellefonte, PA, USA).

\subsection{Vials for air sampling}

Prior to experiments, $20 \mathrm{~mL}$ crimp-top glass vials (HTA, Brescia, Italy) were washed by distilled water and pre-conditioned at $160^{\circ} \mathrm{C}$ for $4 \mathrm{~h}$. Vials were filled with air samples by shaking open vials for $\sim 60 \mathrm{sec}$ to increase air exchange and then leaving them open for 5-15 min. After sampling, vials were crimped by aluminum caps with polytetrafluoroethylene (PTFE)/Silicone septa (SUN-SRi, Rockwood, TN, USA). Crimp-top vials were chosen over screw top vials to minimize sample losses based on preliminary experiments comparing performance of both vial types.

\subsection{Preparation of calibration samples}

To prepare air samples with different standard additions of analytes, $1.00 \mu \mathrm{L}$ of standard solutions containing different analytes concentrations were injected to $20 \mathrm{~mL}$ vials filled with lab air. Vials were crimped immediately after injection of standards. At such conditions, relative 
standard deviations (RSDs) of BTEX masses extracted were consistently below $10 \%$ when $100 \mu \mathrm{m}$ PDMS fiber was used. Increase of injection volume did not result in the decrease of precision as measured by RSDs. The detailed description of the strategy for preparation of calibration samples is given in Supplemental Material (SM).

\subsection{Parameters of GC-MS analyses}

Analyses were conducted on 7890A/5975C Triple-Axis Detector diffusion pump-based GCMS equipped with a split/splitless inlet (Agilent, USA) and Combi-PAL (CTC Analytics, Switzerland) autosampler capable of automated SPME. For separation of BTEX, a $30 \mathrm{~m} \times 0.25 \mathrm{~mm}$ HP-INNOWax (Agilent, USA) column with film thickness $0.25 \mu \mathrm{m}$ was used. The constant flow of He in column was $1 \mathrm{~mL} \mathrm{m^{-1 }}$. Thermal desorption of analytes from SPME fiber in GC injector was done in a splitless mode at $250{ }^{\circ} \mathrm{C}$ using $0.75 \mathrm{~mm}$ i.d. liner (Supelco, USA). Oven temperature was programmed from initial $40{ }^{\circ} \mathrm{C}$ (held for $3 \mathrm{~min}$ ) to $150{ }^{\circ} \mathrm{C}$ (held for $1.5 \mathrm{~min}$ ) at the heating rate of 20 ${ }^{\circ} \mathrm{C} \min ^{-1}$.

For validation of the proposed calibration approach (Section 3.2.1), a 6890N/5973N diffusion pump-based GC-MS equipped with a split/splitless inlet (Agilent, USA) and Combi-PAL (CTC Analytics, Switzerland) autosampler was used. For separation, a $60 \mathrm{~m} \times 0.25 \mathrm{~mm}$ DB-WAXetr (Agilent, USA) column with film thickness $0.50 \mu \mathrm{m}$ was used. Oven temperature was programmed from initial $40{ }^{\circ} \mathrm{C}$ (held for $1 \mathrm{~min}$ ) to $160{ }^{\circ} \mathrm{C}$ (held for $2 \mathrm{~min}$ ) at the heating rate of $10{ }^{\circ} \mathrm{C} \mathrm{min}^{-1}$.

Temperatures of ion source, quadrupole and MS interface of both instruments were 230, 150 and $250^{\circ} \mathrm{C}$, respectively. Detection was conducted using electron impact ionization at $70 \mathrm{eV}$ in selected ion monitoring (SIM) mode at $\mathrm{m} / \mathrm{z}$ of 78, 91, 106 and $106 \mathrm{amu}$ for selective detection and quantification of benzene, toluene, ethylbenzene and $o$-xylene, respectively. For quantification of 
ethylbenzene and $o$-xylene, $\mathrm{m} / \mathrm{z} 106$ was monitored in favor of the more abundant $\mathrm{m} / \mathrm{z} 91$ amu due to higher signal-to-noise ratio and lower potential matrix interferences.

\subsection{Methodology of experiments}

\subsubsection{Validation of the proposed calibration approach}

Vials were filled with laboratory air $(\mathrm{T}=300 \mathrm{~K})$ or outside air $(\mathrm{T}=274 \mathrm{~K})$, spiked with BTEX standards (section 2.2), sealed and placed into the Combi-PAL agitator for further analysis by SPME-GC-MS. SPME from vials containing air samples was conducted at $30{ }^{\circ} \mathrm{C}$ for 3 min using both $100 \mu \mathrm{m}$ PDMS and $85 \mu \mathrm{m}$ CAR/PDMS fibers.

\subsubsection{Comparison of the repeatability when using calibrated gas sampling bulb and $20 \mathrm{~mL}$ vials.}

Prior to air sampling, two 250-mL calibrated gas sampling bulbs (Sigma-Aldrich, St. Louis, MO, USA) were washed by distilled water and pre-conditioned at $160{ }^{\circ} \mathrm{C}$ for $4 \mathrm{~h}$. Ambient air samples were collected by pumping at a flow rate of $1 \mathrm{~L} \mathrm{~min}^{-1}$ for $5 \mathrm{~min}$. Sampling to three replicate vials was conducted as described in Section 2.2. All samples were extracted using $100 \mu \mathrm{m}$ PDS fiber at $30^{\circ} \mathrm{C}$ for $3 \mathrm{~min}$ and analyzed by GC-MS.

\subsection{Air sampling and analysis}

Samples were collected at six sites located in five different districts (Bostandyk, Auezov, Medeu, Almaly and Turksib) of Almaty city, Kazakhstan [22]. These sites, labeled S1-S6, were chosen in different parts of the city for assessment of average and representative pattern of BTEX in the whole city (Table S1). Samples were taken 1.5-1.8 $\mathrm{m}$ above the ground, (i.e., in the inhalation zone for pedestrians), at the distance $>15 \mathrm{~m}$ from the road traffic. Meteorological parameters such as 
temperature, wind speed and humidity of the air (Table S2) were obtained from a publicallyavailable database [23].

Air sampling was done on March 31, April 2 and 4, 2015. Sampling at each location was carried out at 8 a.m. and 8 p.m. Air samples were collected into $20 \mathrm{~mL}$ vials in triplicates. Vials were packed into 1-L clean glass jars, sealed and transported to the laboratory (Fig. S1). Concentrations of BTEX inside vials with a 'clean' air stored using the proposed approach did not increase over a 12-day period (Fig. S2) proving that this simple and practical strategy works well. Sample vials were removed from jars immediately before the analysis to minimize interferences to BTEX concentrations. All air samples were analyzed within $4 \mathrm{~h}$ after collection using $100 \mu \mathrm{m}$ PDMS fiber, controlled extraction temperature of $30{ }^{\circ} \mathrm{C}$, and time $=3 \mathrm{~min}$. Outliers among three replicate measurements were detected and discarded from calculations if RSDs were $>30 \%$.

\section{Results and Discussion}

\subsection{Optimization of the method}

\subsubsection{Development of a simple and practical calibration approach}

Presence of BTEX in the air is a common challenge for many air quality laboratories where special air handling and conditioning is not feasible. To overcome the issue of BTEX presence in the indoor air of the lab, calibration plots were obtained by a standard addition method. The advantage of such methodology is that it does not necessarily require knowing true concentrations of analytes in calibration samples because the obtained calibration slope is assumed equal to the slope for external standard calibration. The proposed approach substantially simplifies a calibration process because 'zero' air is not required for the calibration. 
Obtained calibration plots for BTEX were linear in the whole studied standard addition concentrations range being 20-200 $\mu \mathrm{g} \mathrm{m}^{-3}$ for benzene and toluene and 2-20 $\mu \mathrm{g} \mathrm{m}^{-3}$ for ethylbenzene and $o$-xylene (Fig. S3) with squared correlation coefficients $\mathrm{R}^{2}>0.99$ (Table S3). Selected BTEX concentration ranges are consistent with those needed for studying polluted urban and indoor air. Mean RSDs ranged from 1 to 5\%. According to the calibration, concentrations of benzene, toluene, ethylbenzene and $o$-xylene in lab air were $63,44,2.0$ and $3.0 \mu \mathrm{g} \mathrm{m}^{-3}$, respectively.

\subsubsection{Validation of the proposed calibration approach}

In-laboratory prepared calibration standards and ambient air samples differ by chemical composition and atmospheric pressure. The goals of this experiment was (1) to compare calibration plots obtained using a laboratory air $(\mathrm{T}=300 \mathrm{~K})$ and ambient air $(\mathrm{T}=274 \mathrm{~K})$ and $(2)$ estimate potential matrix effect using two different fiber coatings - absorptive PDMS and adsorptive CAR/PDMS. The PDMS/DVB fiber coating was discarded from further consideration because the addition of $1 \mu \mathrm{L}$ methanol to the analyzed air sample resulted in the $>2$-fold decrease of BTEX peak areas when this coating was used. It was probably caused by the competition between methanol and analytes for adsorption sites.

For PDMS fiber, slope factors of calibration plots obtained using outdoor air were $\sim 10 \%$ higher than those obtained using laboratory air (Table 2) for all analytes. It was probably due to a higher water vapor pressure in a warmer laboratory air and thus lower extraction effectiveness that is in agreement with previously published data [15]. 
Table 2. Slope factors of calibration plots obtained using lab $(\mathrm{T}=300 \mathrm{~K})$ and outdoor $(\mathrm{T}=274 \mathrm{~K})$ air, and measured ambient air concentrations

\begin{tabular}{|c|c|c|c|c|c|}
\hline \multirow[b]{2}{*}{ Analyte } & \multicolumn{2}{|c|}{ Slope factor } & \multirow{2}{*}{$\begin{array}{c}\text { Ambient air } \\
\text { intercept }\end{array}$} & \multirow{2}{*}{$\begin{array}{c}\text { Measured ambient air } \\
\text { concentration, } \mu \mathrm{g} \mathrm{m}^{-3} \text { (recovery, \%) } \\
\text { using lab air slope }\end{array}$} & \multirow{2}{*}{$\begin{array}{l}\text { True ambient air } \\
\text { concentration*, } \\
\qquad \mathrm{g} \mathrm{m}^{-3}\end{array}$} \\
\hline & Lab air & Ambient air & & & \\
\hline \multicolumn{6}{|c|}{$100 \mu \mathrm{m}$ PDMS } \\
\hline Benzene & $20 \pm 2$ & $22 \pm 1$ & $540 \pm 100$ & $26.9(111)$ & $24.2 \pm 4.8$ \\
\hline Toluene & $73 \pm 6$ & $79 \pm 2$ & $3720 \pm 180$ & $51.3(109)$ & $47.0 \pm 2.5$ \\
\hline Ethylbenzene & $63 \pm 2$ & $71 \pm 2$ & $686 \pm 20$ & $11.0(113)$ & $9.7 \pm 0.4$ \\
\hline$o$-Xylene & $106 \pm 3$ & $121 \pm 1$ & $1280 \pm 12$ & $12.1(114)$ & $10.6 \pm 0.2$ \\
\hline \multicolumn{6}{|c|}{$85 \mu \mathrm{m}$ CAR/PDMS } \\
\hline Benzene & $550 \pm 30$ & $600 \pm 30$ & $13600 \pm 3400$ & $24.7(110)$ & $22.5 \pm 5.7$ \\
\hline Toluene & $780 \pm 10$ & $750 \pm 30$ & $38000 \pm 3000$ & $48.6(95)$ & $50.9 \pm 4.3$ \\
\hline Ethylbenzene & $280 \pm 20$ & $270 \pm 30$ & $2600 \pm 300$ & $9.3(96)$ & $9.7 \pm 1.5$ \\
\hline$o$-Xylene & $420 \pm 30$ & $380 \pm 40$ & $4240 \pm 460$ & $10.0(89)$ & $11.2 \pm 1.7$ \\
\hline
\end{tabular}

Note: * determined by a standard addition

Responses to analytes using the CAR/PDMS fiber were 3- to 25-fold higher compared to those for PDMS fiber (Table 2). Due to higher extraction effectiveness, the CAR/PDMS fiber coating was less matrix-affected (i.e., the difference of slope factors was within standard deviations). RSDs for the CAR/PDMS fiber coating were 2 to 3 times greater compared to PDMS coating. This is likely caused by the competition between methanol and BTEX for adsorption sites on the porous CAR/PDMS coating.

Both $100 \mu \mathrm{m}$ PDMS and $85 \mu \mathrm{m}$ CAR/PDMS coatings provided similar accuracies. The use of $100 \mu \mathrm{m}$ PDMS resulted in higher precision associated with a better reliability during calibration (i.e., analysis of a lower number of replicate calibration standards is required), and provided

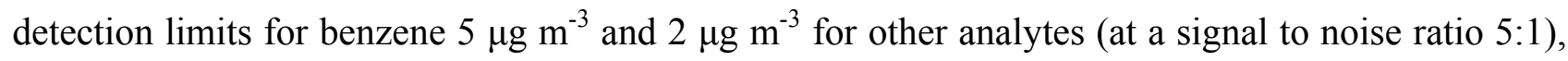
which is sufficient for their quantification at most regulatory levels. At concentration levels below 5 $\mu \mathrm{g} \mathrm{m}^{-3}$, accuracies may be insufficient making the CAR/PDMS coating is a better choice. To 
improve accuracy, calibration standards may be obtained using outdoor air, which is closer to the temperature and humidity of real samples.

\subsubsection{Comparison of extraction from calibrated gas sampling bulbs and $20 \mathrm{~mL}$ vials.}

Masses extracted from $250 \mathrm{~mL}$ glass bulbs were 3\%, 17\%, 18\% and $9 \%$ higher than those from $20 \mathrm{~mL}$ vials for benzene, toluene, ethylbenzene and o-xylene, respectively (Table S4), due to a higher total mass of analytes present within the greater sample volume. Such relatively small differences may be explained by low analytes pre-concentration factors of $100 \mu \mathrm{m}$ PDMS fiber coating [17]. Differences in masses extracted from the bulb and vial will not affect accuracy of real air sample analyses because variations in extraction effectiveness will be included into a slope factor of external standard calibration. RSDs for calibrated bulbs were two times lower than those for 20 mL vials. The highest RSD (20\%) was observed for benzene in $20 \mathrm{~mL}$ vials, most likely, due to small leaks in replicate samples and proximity of concentration to detection limits. Therefore, to achieve sufficient accuracy and reliability using $20 \mathrm{~mL}$ vials, at least three replicates for every sample are recommended. The use of common vials is recommended over specialized air sampling bulbs to keep this method simpler and cost effective.

3.2 Application of the developed method for quantification of BTEX in ambient air of Almaty, Kazakhstan

\subsubsection{Measured concentrations}

The developed method (Fig. 1) was successfully applied for monitoring of BTEX in ambient air in Almaty, Kazakhstan. Mean concentrations (for all 18 air samples at all six locations) of benzene, toluene, ethylbenzene and $o$-xylene at different sampling periods ranged from 24 to 89 , from 32 to 96 , from 6 to 23 and from 7 to $32 \mu \mathrm{g} \mathrm{m}{ }^{-3}$, respectively (Table 3 ). Average concentrations 
of benzene, toluene, ethylbenzene and $o$-xylene calculated as a mean of all 108 measurements were $53,57,11$ and $14 \mu \mathrm{g} \mathrm{m}^{-3}$, respectively.

Fig. 1. Schematic representation of the developed method for simple and accurate quantification of BTEX in ambient air

Table 3. Mean concentrations of BTEX in Almaty ambient air at different time periods

\begin{tabular}{|c|c|c|c|c|c|c|c|c|c|c|c|}
\hline \multirow{3}{*}{\multicolumn{2}{|c|}{ Time of sampling > }} & \multicolumn{10}{|c|}{ Concentration \pm Standard Deviation, $\mu \mathrm{g} \mathrm{m}^{-3}$} \\
\hline & & \multicolumn{3}{|c|}{ 8:00 a.m. } & \multicolumn{3}{|c|}{ 8:00 p.m. } & \multicolumn{3}{|c|}{ Daily } & \multirow{2}{*}{ All } \\
\hline & & March 31 & April 2 & April 4 & March 31 & April 2 & April 4 & March 31 & April 2 & April 4 & \\
\hline \multirow{3}{*}{ Benzene } & Mean & $85 \pm 23$ & $89 \pm 73$ & $26 \pm 10$ & $63 \pm 17$ & $33 \pm 10$ & $24 \pm 3$ & $74 \pm 23$ & $61 \pm 58$ & $25 \pm 7$ & $53 \pm 41$ \\
\hline & Max & 122 & 237 & 37 & 88 & 51 & 27 & 122 & 237 & 43 & 237 \\
\hline & Min & 58 & 46 & 17 & 43 & 21 & 20 & 43 & 23 & 17 & 17 \\
\hline \multirow{3}{*}{ Toluene } & Mean & $43 \pm 22$ & $96 \pm 195$ & $46 \pm 30$ & $59 \pm 41$ & $62 \pm 32$ & $32 \pm 13$ & $51 \pm 33$ & $79 \pm 134$ & $39 \pm 23$ & $56 \pm 80$ \\
\hline & Max & 82 & 494 & 98 & 133 & 100 & 55 & 133 & 494 & 98 & 494 \\
\hline & Min & 26 & 10 & 24 & 18 & 22 & 19 & 18 & 10 & 19 & 10 \\
\hline \multirow{3}{*}{ Ethylbenzene } & Mean & $8 \pm 3$ & $23 \pm 42$ & $10 \pm 8$ & $13 \pm 8$ & $10 \pm 4$ & $6 \pm 1$ & $10 \pm 7$ & $16 \pm 30$ & $7 \pm 4$ & $11 \pm 17$ \\
\hline & Max & 13 & 108 & 20 & 27 & 17 & 7 & 27 & 107 & 20 & 107 \\
\hline & Min & 6 & 4 & 5 & 4 & 4 & 5 & 4 & 4 & 5 & 4 \\
\hline \multirow{3}{*}{$o$-Xylene } & Mean & $9 \pm 4$ & $32 \pm 66$ & $10 \pm 8$ & $15 \pm 10$ & $13 \pm 7$ & $7 \pm 2$ & $12 \pm 8$ & $22 \pm 46$ & $8 \pm 6$ & $14 \pm 27$ \\
\hline & Max & 15 & 166 & 24 & 31 & 22 & 9 & 31 & 166 & 24 & 166 \\
\hline & Min & 6 & 3 & 5 & 3 & 4 & 4 & 3 & 3 & 4 & 3 \\
\hline
\end{tabular}

RSDs of triplicate ambient air measurements did not exceed $25 \%$ with most replicates being in the range of $10 \%$, which is excellent and sufficient considering the simplicity of the approach for sampling of ambient air. Over the whole study, only twelve 'outliers' were detected $(<11 \%$ of total samples), likely caused by leak from improperly crimped vials.

Concentrations of BTEX in Almaty, Kazakhstan are within the range of reported concentrations of BTEX in cities with major air quality problems such as New Delhi, Cairo, Rome, Ho Chi Minh City, Sao Paulo, or Manila (Table S5) where vehicle exhausts are the main sources of 
BTEX, similarly to earlier reports from Almaty $[21,24]$. The main difference of Almaty from these cities is a colder climate requiring heavy use of heating system in October-April. In Almaty, a substantial part of annual air pollution (about 20\%) originates from emissions of power plants and private residential heating systems [21].

\subsubsection{Identification of BTEX emission sources}

Toluene-to-benzene concentrations (T/B) ratio in ambient air depends on the main source of air pollution, distance from the source and environmental conditions $[4,25,26]$, thus the $\mathrm{T} / \mathrm{B}$ ratio can be useful for source apportionment studies. The T/B ratio in the studied air samples increased with increasing temperature of a sampled air (Fig. S4), however, linearity of the plot is assumed for simplicity with no evidence for the actual type of relation. Five measurements provided T/B ratios greater than 2 with the highest T/B ratio (3.4) observed in Turksib district. At sub $0{ }^{\circ} \mathrm{C}$ sampling temperatures, T/B ratios were below 1.0 in 15 out of 18 samples. Such ratios may indicate that significant fractions of BTEX at the time of sampling originated from non-traffic related sources $[27,28]$. At lower temperatures, main sources of BTEX are most likely originating from power plants and residential heating, most of which still use coal as a fuel. On Saturday evening, the T/B ratio was close to 1.0 in $50 \%$ of sampling locations because the volume of traffic on weekends is much lower than that of weekdays.

\section{Conclusions}

A simple method for quantification of BTEX concentrations in ambient air was developed utilizing standard, cost effective crimp-top 20-mL headspace vials for air sampling in the field, SPME for headspace extractions, and GC-MS for analyses. For quantification of BTEX, external standard method was used, however, slope factors of calibration plots were determined by a 
standard addition method, which did not require a 'zero' air. Transportation and storage of samples in an additional low-cost $1 \mathrm{~L}$ sealed glass jars minimized the effects of sample leaks.

Slope factors of calibration plots obtained with a high moisture content lab air $(\mathrm{T}=300 \mathrm{~K}$, $\mathrm{RH}=70-80 \%)$ were $9-14 \%$ lower than those obtained with a cooler and drier outdoor $(\mathrm{T}=274 \mathrm{~K})$ air, probably, due to the effect of water vapor pressure on the extraction effectiveness by the $100 \mu \mathrm{m}$ PDMS fiber. Use of the CAR/PDMS fiber coating was associated with RSDs being 2 to 3 times higher than the values observed using the PDMS coating, likely due to the more pronounced competition for adsorption sites present on the CAR/PDMS fiber between the analytes and the methanol used as the solvent for spiked standards.

Compared to calibrated $250 \mathrm{~mL}$ gas sampling bulbs, $20 \mathrm{~mL}$ headspace vials provided 2 times higher RSDs reaching $20 \%$ for benzene, however, the sufficient accuracy was achieved by collecting and analyzing triplicate samples. The use of $20 \mathrm{~mL}$ vials allows automation of calibration and analysis, which makes it possible to collect and analyze a larger number of samples.

This method was successfully applied for the analysis of 108 ambient air samples taken at six different time periods and six locations within Almaty, Kazakhstan. The number of samples analyzed daily $(\mathrm{n}=36)$ using a single GC-MS instrument is greater than any previously reported study for a SPME-based air sampling study. Mean concentrations of benzene, toluene, ethylbenzene and $o$-xylene ranged from 24 to 89 , from 32 to 96 , from 6 to 23 and from 7 to $32 \mu \mathrm{g} \mathrm{m}^{-3}$, respectively. Mean BTEX concentrations over all locations and sampling periods were 53, 57, 11 and $14 \mu \mathrm{g} \mathrm{m}^{-3}$, respectively. These values are comparable with those in the most polluted cities around the world.

Compared to other available SPME-based methods, the developed method is simpler, faster, more labor and cost efficient, and does not require complex or expensive calibration equipment. This method provides a good alternative for low-budget air quality monitoring for BTEX, and is amenable to the addition of other target VOCs of concern in urban air quality assessment. Sampling 
with simple vials presents an opportunity to consider 'crowd-sourcing' as a means for even more cost-efficient air quality studies.

\section{Acknowledgements}

The work was supported by the grant from the Ministry of Education and Science of the Republic of Kazakhstan 4185/GF4 "Development of semi-automatic station for monitoring concentrations of volatile organic contaminants in ambient air of cities using chromatographic methods".

Authors would like to thank Dr. Christine Ellis (USDA-APHIS-WS-National Wildlife Research Center) and Somchai Rice (Iowa State University) for their comments and improvements to the final version of the manuscript.

\section{References}

[1] WHO, Air quality deteriorating in many of the world's cities. News release., (2014). http://www.who.int/mediacentre/news/releases/2014/air-quality/en/ (accessed September 8, 2015).

[2] M. Alghamdi, M. Khoder, Seasonal and diurnal variations of BTEX and their potential for ozone formation in the urban background atmosphere of the coastal city Jeddah, Saudi Arabia, Atmos. Environ. 94 (2014) 205-214. doi:10.1016/j.atmosenv.2014.03.029.

[3] A.L. Bolden, C.F. Kwiatkowski, T. Colborn, New look at BTEX: are ambient levels a problem?, Environ. Sci. Technol. 49 (2015) 5261-5276. doi:10.1021/es505316f.

[4] R. Kerbachi, M. Boughedaoui, L. Bounoua, M. Keddam, Ambient air pollution by aromatic hydrocarbons in Algiers, Atmos. Environ. 40 (2006) 3995-4003. 
doi:10.1016/j.atmosenv.2006.02.033.

[5] M. Caselli, G. de Gennaro, A. Marzocca, L. Trizio, M. Tutino, Assessment of the impact of the vehicular traffic on BTEX concentration in ring roads in urban areas of Bari (Italy), Chemosphere. 81 (2010) 306-311. doi:10.1016/j.chemosphere.2010.07.033.

[6] C. Feng, S. Mitra, Breakthrough and desorption characteristics of a microtrap, J. Microcolumn Sep. 12 (2000) 267-275. doi:10.1002/(SICI)1520-667X(2000)12:4<267::AIDMCS11>3.0.CO;2-B.

[7] U.S. EPA, Method TO-17 "Determination of volatile organic compounds in ambient air using active sampling onto sorbent tubes," (1999).

[8] U.S. EPA, Method TO-15 "Determination of volatile organic compounds (VOCs) in air collected in specially-prepared canisters and analyzed by gas chromatography/mass spectrometry (GC/MS)," (2004).

[9] K. Elke, E. Jermann, Determination of benzene, toluene, ethylbenzene and xylenes in indoor air at environmental levels using diffusive samplers in combination with headspace solidphase microextraction and high-resolution gas chromatography-flame ionization detection, J. Chromatogr. A. 826 (1998) 191-200. doi:10.1016/S0021-9673(98)00736-5.

[10] A. Khaled, J. Pawliszyn, Time-weighted average sampling of volatile and semi-volatile airborne organic compounds by the solid-phase microextraction device, J. Chromatogr. A. 892 (2000) 455-467. doi:10.1016/S0021-9673(00)00295-8.

[11] P.A. Martos, J. Pawliszyn, Time-weighted average sampling with solid-phase microextraction device: Implications for enhanced personal exposure monitoring to airborne pollutants, Anal. Chem. 71 (1999) 1513-1520. doi:10.1021/ac981028k.

[12] M. Chai, J. Pawliszyn, Analysis of environmental air samples by solid-phase microextraction and gas chromatography / ion trap mass spectrometry, Environ. Sci. Technol. 29 (1995) 693701. doi:10.1021/es00003a017. 
[13] M. Chai, Y.-Z. Tang, Solid phase microextraction (SPME) analysis of whole air samples, Int. J. Environ. Anal. Chem. 72 (1998) 77-82. doi:10.1080/03067319808032645.

[14] M. Hippelein, Analysing selected VVOCs in indoor air with solid phase microextraction (SPME): a case study, Chemosphere. 65 (2006) 271-7.

doi:10.1016/j.chemosphere.2006.02.041.

[15] P.A. Martos, J. Pawliszyn, Calibration of solid phase microextraction for air analyses based on physical chemical properties of the coating, Anal. Chem. 69 (1997) 206-215. doi:10.1021/ac960415w.

[16] J.A. Koziel, J. Pawliszyn, Air sampling and analysis of volatile organic compounds with solid phase microextraction., J. Air Waste Manag. Assoc. 51 (2001) 173-184. doi:10.1080/10473289.2001.10464263.

[17] L. Tuduri, V. Desauziers, J.L. Fanlo, Potential of solid-phase microextraction fibers for the analysis of volatile organic compounds in air., J. Chromatogr. Sci. 39 (2001) 521-529. doi:10.1093/chromsci/39.12.521.

[18] S. Tumbiolo, J.-F. Gal, P.-C. Maria, O. Zerbinati, Determination of benzene, toluene, ethylbenzene and xylenes in air by solid phase micro-extraction/gas chromatography/mass spectrometry, Anal. Bioanal. Chem. 380 (2004) 824-830. doi:10.1007/s00216-004-2837-1.

[19] S. Tumbiolo, J.-F. Gal, P. Maria, O. Zerbinati, SPME sampling of BTEX before GC/MS analysis: examples of outdoor and indoor air quality measurements in public and private sites, Ann. Chim. 95 (2005) 757-766. doi:10.1002/adic.200590089.

[20] N. Baimatova, J. Koziel, B. Kenessov, Quantification of benzene, toluene, ethylbenzene and o-xylene in internal combustion engine exhaust with time-weighted average solid phase microextraction and gas chromatography mass spectrometry, Anal. Chim. Acta. 873 (2015) 38-50. doi:10.1016/j.aca.2015.02.062.

[21] L. Carlsen, B. Kenessov, N. Baimatova, Assessment of the air quality of Almaty. Focussing 
on the traffic component, Int. J. Biol. Chem. 49 (2013) 49-69.

[22] B. Kenessov, Location of sampling points for ambient air sampling in Almaty, Kazakhstan, (2015).

https://www.google.com/maps/d/edit?mid=zaVQM9knLobU.kSwNxxgjpLpo\&usp=sharing (accessed January 1, 2016).

[23] Kazhydromet, Weather in Almaty on March 2015, (2015).

[24] J.A.G. Balanay, C.T. Lungu, Exposure of jeepney drivers in Manila, Philippines, to selected volatile organic compounds (VOCs)., Ind. Health. 47 (2009) 33-42.

doi:10.2486/indhealth.47.33.

[25] M.I. Khoder, Ambient levels of volatile organic compounds in the atmosphere of Greater Cairo, Atmos. Environ. 41 (2007) 554-566. doi:10.1016/j.atmosenv.2006.08.051.

[26] H. Guo, K.L. So, I.J. Simpson, B. Barletta, S. Meinardi, D.R. Blake, C1-C8 volatile organic compounds in the atmosphere of Hong Kong: overview of atmospheric processing and source apportionment, Atmos. Environ. 41 (2007) 1456-1472. doi:10.1016/j.atmosenv.2006.10.011.

[27] C.Y. Moreira dos Santos, D. de Almeida Azevedo, F.R. de Aquino Neto, Atmospheric distribution of organic compounds from urban areas near a coal-fired power station, Atmos. Environ. 38 (2004) 1247-1257. doi:10.1016/j.atmosenv.2003.11.026.

[28] K. Liu, C. Zhang, Y. Cheng, C. Liu, H. Zhang, G. Zhang, et al., Serious BTEX pollution in rural area of the North China Plain during winter season., J. Environ. Sci. 30 (2015) 186-90. doi:10.1016/j.jes.2014.05.056. 


\section{Figure Preparation of} calibration standards

BTEX standards in methanol

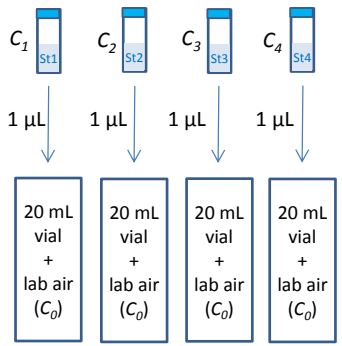

6) Data processing

=
2) SPME-GC-MS of prepared standards

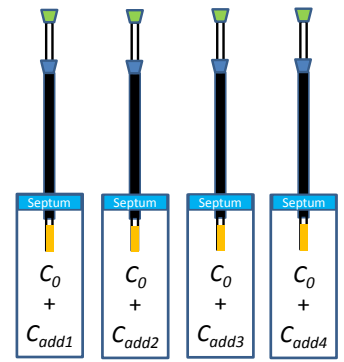

\section{3) Constructing} calibration plots

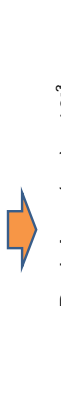

- Benzene
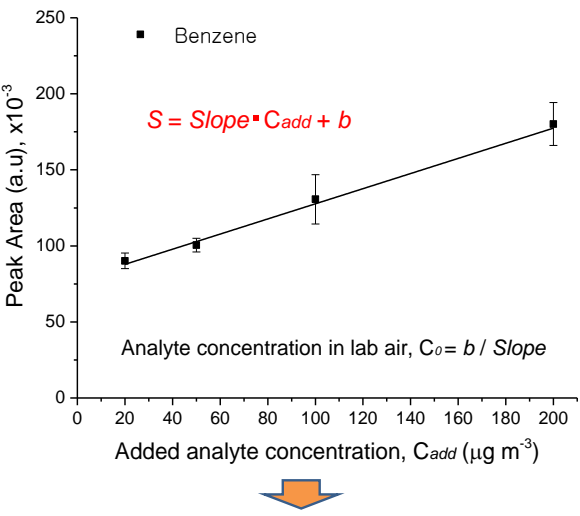

5) SPME-GC-MS 4) Air sampling + transportation of samples
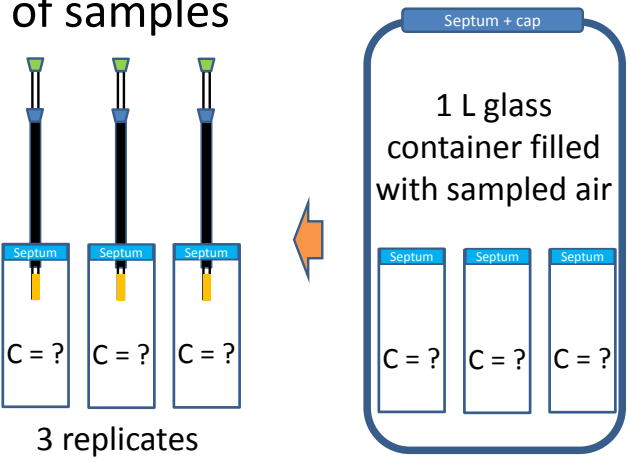
vials for $60 \mathrm{sec}$ and leaving them open for $5 \mathrm{~min}$;

crimping

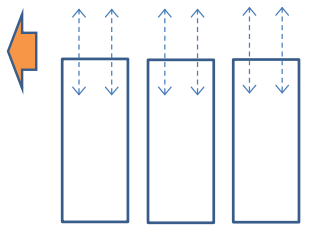

3 replicates 


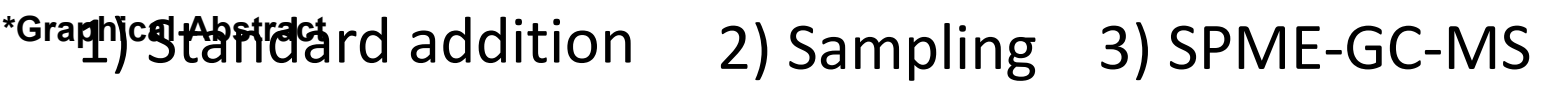

\section{calibration}

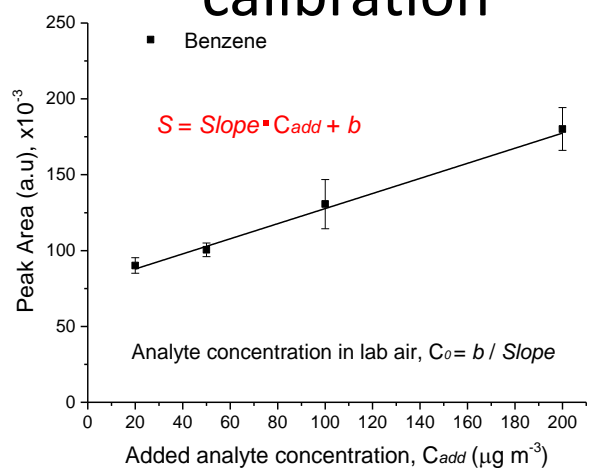

\section{Septum + cap}

$1 \mathrm{~L}$ glass container filled with sampled

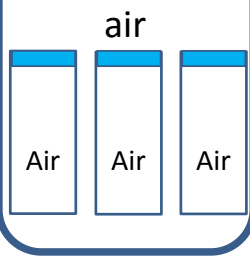

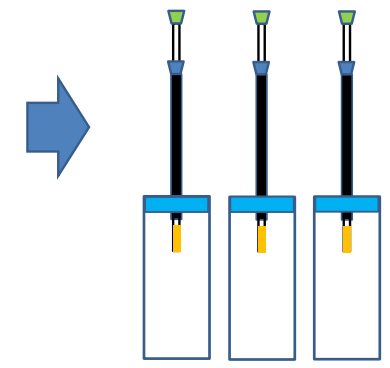

